\title{
Medicolegal
}

\section{Dr Gee defends his treatment}

\author{
CLARE DYER
}

After Lord Justice Croom-Johnson's apparently unprecedented decision to discharge the jury and try the rest of the case alone, Dr Sidney Gee's libel action against the BBC and two other doctors (17 November, p 1086; 24 November, p 1460; 1 December, p 1530) continued last week, with Dr Gee still in the witness box undergoing cross examination by Andrew Rankin QC, leading counsel for the BBC.

Mr Rankin questioned Dr Gee at length about his compliance with the legal obligations applying to doctors who supply drugs. Dr Gee admitted that he was unaware that he was required under the Labelling Regulations to write the date that he supplied a medicine on the container. In that respect, he conceded, Gavin Campbell, assistant presenter of That's Life, had been technically correct when he said: "You are prescribing a controlled drug without marking it properly."

Counsel went on to inquire about Dr Gee's controlled drugs register. Dr Gee accepted that, contrary to the regulations, the dates stamped in the register in many cases did not correlate with the dates that drugs were supplied. He said that his staff stamped the book sometimes days ahead, and he had not reminded them of their obligations under the regulations.

After putting several general questions about the drugs register counsel asked Dr Gee about one of his patients, Mrs Downs. Dr Gee agreed that Mrs Downs had been to see him on four occasions: 4 August, 25 August, 11 September, and 6 October. Mr Rankin asked when the date annotations in the drugs register had been made. $\mathrm{Dr}$ Gee replied that he was not able to say. To counsel's suggestion that the annotations had been made only because of the legal proceedings Dr Gee answered that they might well have been.

$\mathrm{Mr}$ Rankin referred to a previous answer of Dr Gee, in which he had said that every annotation had been made on the day it was dated. Dr Gee replied that in normal circumstances that was the case. But if he had had to check specially to find out when a patient came he would mark the date at the bottom of the page, so that when he had to find it for other legal purposes he could just turn it up.

Dr Gee admitted that very little information about his patients was recorded in his records. He agreed that Mrs Downs's record contained only her age, weight, blood pressure, and pulse and the date on which she first saw Dr Gee. There was no information recorded about her medical history. In reply to counsel's question Dr Gee said he would not disagree if Mrs Downs were to say that she had told him of a family history of diabetes and high blood pressure, but he would not consider it relevant in her treatment. Nor had he asked her whether she was taking the contraceptive pill. He did not give his treatment to women known to be pregnant, but his drugs had no harmful effects during the first three months of pregnancy. He conceded that he did not make it a practice to ask women of child bearing age whether they were trying to become pregnant, but he asked every woman patient when her period was due. If any of his

London NW1

CLARE DYER, BA, BLS, solicitor and legal journalist patients became pregnant he would give her no further drug treatment.

In response to a question from Mr Rankin Dr Gee said he did not regard Mrs Downs's weight loss-23 pounds in the first three weeks - as out of the way for a person of 21 stone. He denied having told Mrs Downs to skip but said that he told all patients of that weight to walk for 30 minutes and make sure that they raised the pulse rate, or to use an exercise record or tape. He denied that he had told Mrs Downs to use an exercise bike until she felt exerted.

Mr Rankin suggested to Dr Gee that when Mrs Downs made her third visit she told him that she thought she might be pregnant. He said that if she had done so he would not have given her treatment and made another appointment. Her obstetrician and gynaecologist had told him that she became pregnant on 2 or 3 November, nearly a month after he last saw her and gave her a 21 day supply of tablets on 6 October. Mr Rankin said that Mrs Downs would tell the judge that according to her general practitioner's calculations the date of conception was on or about 18 October. (The child was stillborn.)

Questioned about another patient, Gillian Malone, recorded as weighing 21 stone 11 pounds and having a blood pressure of $150 / 100 \mathrm{~mm} \mathrm{Hg}$, Dr Gee agreed that she had been put on tablets three times a day, instead of the usual twice a day. This was to prevent her from feeling at a disadvantage to Mrs Day, with whom she had come, and who was taking the tablets three times a day. The extra atropine and caffeine citrate were not significant, he said.

He described as "ludicrous" counsel's suggestion that he had told Mrs Malone to run up and down stairs till she felt pain in her chest. He had prescribed diazepam for her not because she said she felt hyperactive but because she showed symptoms of a mild anxiety state. He had several articles, he insisted, which showed that $5 \mathrm{mg}$ amphetamine had no effect on mood. Counsel asked whether Mrs Malone's feeling that her heart was beating quickly could be due to the drug treatment. Dr Gee replied that he could not say that the thyroid extract would have had nothing to do with it.

\section{Altered entries in register}

Mr Rankin referred Dr Gee to some alterations in the entries in the drugs register relating to Mrs White, a patient who died of cardiorespiratory failure on 4 July 1983 and at whose inquest Dr Gee had given evidence. (An open verdict was returned.) Dr Gee said he had made the alterations on the second day after the $\mathrm{BBC}$ broadcast. Counsel suggested that before the page was altered the dispensing of drugs to Mrs White had been dated earlier than 30 June. Dr Gee denied it. Mr Rankin put it to Dr Gee that some of the dates had been altered twice; Dr Gee denied that this had been so with the 30 June date. Mr Rankin pointed out that Mrs White's entry for 30 June was in a different ink from any of the other entries that Dr Gee had made dated 30 June.

Counsel referred Dr Gee to Mrs White's NHS general practitioner's records. Dr Gee agreed that they showed that from March to June 1983, when Mrs White was receiving the Rochester drug treatment, she was seeing her own general practitioner and complaining to him. On 3 May she had received thyroid extract. $\mathbf{M r}$ 
Rankin referred Dr Gee to the entry in her general practitioner's records for 14 May: "My heart pounds and pounds. Lasts up to three hours." Dr Gee agreed that he had carried out no physical examination of Mrs White between the end of March and 30 June 1983. Mr Rankin drew his attention to other entries in her general practitioner's notes: "short of breath," and "aching in the left arm"; to a report on an electrocardiogram ordered by her general practitioner, which indicated sinus tachycardia; and to a later note, on 17 June: "palpitation on exertion."

In response to Mr Rankin's suggestion that some of Mrs White's symptoms might have been to the thyroid extract Dr Gee quoted from several scientific articles to support his contention that most people with a normal thyroid develop a degree of tolerance to thyroid treatment. Mr Rankin emphasised to Dr Gee that his dose of thyroid extract was more than twice the normal replacement dose. Dr Gee replied that the normal replacement dose was an imaginary concept, and that thyroid extract was much less well absorbed than thyroxine or tri-iodothyronine.

Mr Rankin quoted extracts from several textbooks which advised against the use of thyroid medication and amphetamines in treating obesity. Dr Gee countered that these textbooks were written for a middle ground, not someone in his position. He accepted that there was a body of opinion that thought that thyroid hormones should be given only to patients with demonstrated permanent hypothyroidism. It would not be difficult to produce 50 articles supporting the use of thyroid hormones in the treatment of simple obesity uncomplicated by permanent hypothyroidism.

Counsel quoted from a textbook on the thyroid by Werner and Ingba (1971 edition): "The prolonged administration of doses of thyroid, in excess of $180 \mathrm{mg}$ or its equivalent daily is hazardous and completely unjustified." Dr Gee said he disagreed completely: there was no evidence to show that this was so. He said that $180 \mathrm{mg}$ was three quarters of his dosage $(250 \mathrm{mg})$.

$\mathrm{Mr}$ Rankin also referred Dr Gee to an extract from Goodman and Gilman's The Pharmacological Basis of Therapeutics, 6th edition, 1980: "Certain bizarre combinations of thyroid and other drugs (especially amphetamines) are still available. The use of thyroid or such mixtures for the purpose of weight reduction is dangerous and sudden deaths from cardiac arrhythmias have occurred. Obesity is not an acceptable indication for thyroid hormone therapy." Dr Gee denied that there was any record of sudden deaths from the use of either thyroid, or thyroid and amphetamine, in the dosages in which he used them.

MrRankin pressed Dr Gee on the tri-iodothyronine and thyroxine content of his thyroid extract tablets. Dr Gee disagreed with a table from de Groot and Stanbury, Thyroid and its Diseases (1975), which gave $100 \mu \mathrm{g}$ of tri-iodothyronine as the equivalent of $120 \mathrm{mg}$ of desiccated thyroid. He said that in giving patients $250 \mathrm{mg}$ of thyroid extract, he was giving the equivalent of about $50-60 \mu \mathrm{g}$ of triiodothyronine.

\title{
Inside and Outside Europe
}

\section{Medical journals in the Third World: problems and possibilities}

\author{
RICHARD SMITH
}

\begin{abstract}
Producing and editing the fourmal of the Sierra Leone Medical and Dental Association is difficult. The 500 doctors in the country don't always produce enough copy to fill the journal; much of what they do produce has to be heavily edited; the members of the association become upset when there are too many articles from outside Sierra Leone; printing costs are rising rapidly, making the whole operation vulnerable; pressures from advertisers are always a worry; and, as a final insult, many of the Sierra Leone doctors who write a good paper would rather have it published in the Lancet, the $B M \mathcal{F}$, or the East African Medical Fournal. Yet despite these problems, the editor, Dr Durodami Lisk, who was trained in Newcastle, has no doubt that bringing out the journal is worth while and important.
\end{abstract}

\section{WHO is FIPP?}

Dr Lisk's problems were typical of those experienced by the eight other Third World health journal editors who gathered together last month for a conference in Copenhagen. The conference was organised by the International Federation of the Periodical Press (FIPP) together with the World Health Organisation, and the purpose was to bring together Third World editors with those from the developed world. Dr Ole Harlem, the editor of the Norwegian Medical

"British Medical Journal"

RICHARD SMITH, BSC, MB, assistant editor
Fournal and a member of the FIPP editorial committee, conceived the idea, and it took him three years to bring it to fruition.

FIPP represents about 20000 titles from around the world and is interested, the president Mr Fernando Bolin, a Spaniard, said, in both "big and small problems." The main reason for holding this meeting, Ms Jane Reed, the chairman of the editorial committee, explained, was that FIPP was concerned about the division between journalists in the developing and developed world. Those in the developing world feel that they are not listened to in the developed world, that they don't have the same access to information, and that their national views are misrepresented in publications from the developed world. FIPP hoped that by bringing together journalists and editors from the two worlds to discuss an issue "about which people could be objective" some of the hostility would disappear.

This "hidden agenda" remained hidden during most of the two day conference, but most of the editors seemed to feel that something was gained, if mainly the contents of a second conference. Information is, after all, as important as drugs, and maybe WHO should be producing an essential information list as well as an essential drug list. Sadly, the conference spent little or no time discussing what sort of health journals and information were needed in the Third World and much more time in discussing how the information should be packaged, distributed, and paid for. One "young idealist" (me) suggested that what was needed was not so much a plethora of small and inevitably second class New England Fournals of Medicine but more a cheap, practical, and widely available broadsheet that was directed at primary health care workers in remote areas. Maybe this suggestion was an example of the developed world patronising the Third World, but there was some mutter of approval before the meeting moved on. 